\title{
Flexible Adaptation of Leader Behavior
}

\section{An Experimental Analysis of the Beneficial Effect of Flexibility in Innovation Processes}

\author{
Friederike Gerlach¹, Kathrin Rosing', and Hannes Zacher² \\ Institute of Psychology, University of Kassel, Germany \\ ${ }^{2}$ Institute of Psychology - Wilhelm Wundt, Leipzig University, Germany
}

\begin{abstract}
Based on the model of ambidextrous leadership, we investigated the impact of flexible adaptation of leader behavior, that is, opening and closing leader behaviors, on innovative performance in a laboratory experiment. Leader behaviors were manipulated with confederates attending to one participant showing either no leadership, a sequential, or a flexible application of opening and closing leader behaviors. We hypothesized that flexible adaptation leads to better innovation performance. $N=93$ participants took part and received one leadership manipulation. We did not find significant effects. These findings suggest that the effects of ambidextrous leadership might not be as strong as previously expected. Nonetheless, this study provides a manipulation of flexible leadership in a controlled setting, which is important to provide causal evidence.
\end{abstract}

Keywords: experiment, ambidextrous leadership, flexibility

Today's business world is characterized by change (Halbesleben et al., 2003; Hosking \& Anderson, 2018). Accordingly, flexibility and dynamic adaptation have been coined as important prerequisites for successful leadership in different organizational processes (Vroom \& Jago, 2007; Yukl \& Mahsud, 2010). In an increasingly complex business environment, it is important for leaders to be adaptable and respond to the changing requirements of followers and tasks (Blanchard et al., 1993; Yukl \& Mahsud, 2010). This is especially true for innovation processes, as they involve changing situational requirements, including creativity and idea implementation (Bledow et al., 2009). Flexibility has been recognized in theoretical models on leadership, but a thorough empirical investigation of this component of leadership is lacking (Fiedler, 1971; Yukl \& Mahsud, 2010). Therefore, the goal of this study is to examine the effectiveness of a flexible leadership concept for innovation processes.

Regarding innovation processes, the flexible adaptation of leader behavior could be key to an effective leadership approach (Havermans et al., 2015; Rosing et al., 2011). Empirical relationships of traditional leadership approaches, such as transformational leadership, with innovation performance are inconsistent and vary widely (Herrmann \& Felfe, 2013; Rosing et al., 2011). This could be due to the fluctuating requirements of creativity and implementation and a neglect of matching these requirements with appropriate leader behaviors (Rosing et al., 2011, 2018). A flexible adaptation of leader behavior to address both requirements could provide a solution.

The model of ambidextrous leadership describes such an approach, as two leader behaviors, opening and closing, are defined to address creativity and implementation requirements, respectively (Rosing et al., 2011). Most importantly, for successful innovation processes, both behaviors need to be applied flexibly to address the present requirement in each situation (Hunter et al., 2011; Rosing et al., 2011). Although flexibility is at the core of ambidextrous leadership, actual changes between opening and closing leader behaviors have not yet been investigated empirically (Zacher et al., 2016; Zacher \& Rosing, 2015; Zacher \& Wilden, 2014). This is problematic because, based on our knowledge of the innovation process, adequate changes should catalyze the effectiveness of ambidextrous leadership for innovation success (Bledow et al., 2009; Rosing et al., 2011). In addition, the existing literature on leadership for innovation has relied mostly on correlational designs (Hughes et al., 2018). Recent exceptions are the experimental studies by Klonek et al. (2020) and Gerlach, Heinigk et al. (2020) which, however, do not include aspects of flexibility. Thus, 
conclusions in terms of causal influences of flexible adaptation of leader behavior cannot be drawn, for instance, due to possible reverse causality issues (Antonakis, 2017; Antonakis et al., 2010).

This paper considers these limitations and investigates the flexible adaptation of ambidextrous leader behaviors in a controlled laboratory setting. We aim to contribute to the leadership literature in two ways. First, our research provides empirical data on a flexible leadership approach. Second, we give insights on how flexible leadership can be standardized in a laboratory setting to draw causal conclusions and to avoid the issue of reverse causality or the influence of biases such as performance cues (Antonakis, 2017; Lord et al., 1978). In line with this, we highlight the difficulties and challenges associated with such a laboratory experiment (Podsakoff \& Podsakoff, 2019).

\section{Theoretical Background and Hypothesis Development}

\section{Flexibility in Innovation Processes}

Innovation is defined as the "intentional introduction and application within a role, group or organization of ideas, processes, products or procedures, new to the relevant unit of adoption" (West \& Farr, 1990, p. 9). Accordingly, innovation incorporates both requirements of creativity and implementation (Miron-Spektor et al., 2018). Creativity requires the generation of ideas associated with novelty, taking risks, and new opportunities (Amabile, 1988; Amabile \& Pratt, 2016; Andriopoulos \& Lewis, 2009). Implementation requirements, in contrast, entail the efficient and error-free realization of a product or process (Andriopoulos \& Lewis, 2009). Both creativity and implementation requirements are present throughout the whole innovation process (Bledow et al., 2009; Rosing et al., 2018). They fluctuate within the innovation process resulting in situations where creativity requirements and situations in which implementation requirements are more prominent (Rosing et al., 2018). Actors within the innovation process need to adjust their behavior in line with these requirements to address both aspects and integrate them to reach high innovation performance (Rosing et al., 2011, 2018).

\section{Ambidextrous Leadership for Innovation}

Leadership has been suggested as one of the central influences that can support followers in mastering the challenge of innovation (Hunter et al., 2011; Mumford et al., 2002). In general, it has been proposed that leader support for creativity and innovation will be helpful (Mainemelis et al., 2015; Shalley \& Gilson, 2004). The model of ambidextrous leadership specifically describes leadership for innovation by considering the situational requirements of creativity and implementation (Hunter et al., 2011; Rosing et al., 2011). Opening leader behavior describes aspects such as experimenting with different ideas and taking risks, whereas closing leader behavior incorporates controlling goal attainment and emphasizing efficiency (Rosing et al., 2011). According to the model, opening leader behavior should address creativity requirements, whereas closing leader behavior will be helpful when implementation is required (Rosing et al., 2011).

In addition to addressing creativity and implementation requirements, leaders also need to be aware of the dynamic nature of the innovation process (Rosing et al., 2011). The situational requirements of creativity and implementation fluctuate in an unpredictable manner (Bledow et al., 2009; Rosing et al., 2018). In line with this, ambidextrous leaders need to identify creativity and implementation requirements as they are inherent to the tasks of the innovation process (Rosing et al., 2011). They should adjust their leader behavior toward opening leader behavior when creativity is required, whereas they need to adapt to closing leader behavior when implementation requirements are more prominent (Rosing et al., 2011). With the appropriate leader behavior for a given situation, the leader provides information on how to address a certain situational requirement of either creativity or implementation (Herrmann \& Felfe, 2013; Rosing et al., 2011). Moreover, a flexible leadership approach will also provide more effective communication as the leader behavior matches the requirements. Thus, the communication may be perceived as more appropriate and lead to better leader-follower interactions in general (Gottfredson \& Aguinis, 2017; Hofmans et al., 2019).

Appropriate communication and improved leader-follower interactions will not be possible with a strictly sequential approach, showing only opening leader behavior in the beginning to foster creativity and only closing leader behavior toward the end (Farr et al., 2003). Such a sequential approach is advocated by phase models of innovation that prescribe a certain order of innovation phases (Lubart, 2001). Similarly, stage-gate models (Cooper, 1990) propose that the innovation process can be subdivided into phases separated by a "gate." These models imply that once a gate has been passed, it is not possible to go back to a previous phase. Such a sequential approach does not allow for flexibility to address creativity and implementation requirements as they occur within the process (Bledow et al., 2009; Rosing et al., 2011). In 
conclusion, the flexible adaptation of leader behaviors should improve followers' ability to flexibly address creativity and implementation requirements and, thus, should result in higher innovation performance.

Hypothesis: The flexible application of opening and closing leader behaviors leads to better innovation performance compared to (a) no leadership and (b) a sequential application of opening and closing leader behaviors.

\section{Method}

The stage 1 manuscript was registered at the Open Science Framework, https://osf.io/srwcn/?view_only= 84d9ae1860ec499c8929fbde4fcf86d9. Data for the experiment were collected using a between-subjects design manipulating an independent variable with three conditions: no leadership (control group), sequential, and flexible ambidextrous leadership.

\section{Sample}

For the experiment, we recruited $N=107$ students from a German university via social networks or lectures. In total, $n=14$ participants were dropped due to confederates not following the script, technical issues, or language barriers. This led to a final sample size of $N=93$. Participants were randomly assigned to one of the three experimental groups leading to 27-33 participants per group. They were on average 22.91 years old $(S D=4.94)$. Seventy-three participants $(78.5 \%)$ were female, and 20 (21.5\%) were male. They majored in different subjects, and most of them studied psychology (40.9\%).

\section{Power Analysis}

Based on the existing research, we expected a medium sized effect of ambidextrous leadership (Bosco et al., 2015; Zacher \& Rosing, 2015; Zacher \& Wilden, 2014). Thus, we estimated the statistical power with the software $G^{*}$ Power (Faul et al., 2007, 2009) using the expected medium effect $\left(f^{2}=0.15\right), \alpha=.05$, the sample size of $N=93$, three groups, and two response variables. Given these variables, the power is very good, $1-\beta=.99$. Investigating smaller effect sizes, results reveal that the power is sufficient $(1-\beta>.80)$ if the effect size is at least $f^{2}=0.07$. Meta-analytic estimates suggest that this is realistic (Bosco et al., 2015), and therefore, the power of the conducted study should be sufficient.

\section{Procedure}

After they were welcomed at the laboratory, the experimenter informed participants that they would take part in an innovation competition (for experimenter instructions, refer to supplemental materials, https://osf.io/srwcn/? view_only=84d9ae1860ec499c8929fbde4fcf86d9). Participants were told that someone would support them while working on the task. To introduce the confederate as a leader, the experimenter described the person, who was waiting in the other room, as fulfilling tasks inherent to leadership (Yukl, 2012; Yukl et al., 2016). The participants were informed that the person would provide the task information and the goal for the competition. Furthermore, the person would control the adherence to the task instructions and support the participant during task completion. Finally, participants were told that the person would evaluate the task outcome of the competition. Subsequently, the experimenter accompanied the participant to the laboratory, where the confederate was waiting. The confederate gave the instructions for the innovation task and explained that the three best results out of all participants were rewarded with a $€ 50$ voucher. During task completion, confederates showed leader behavior depending on the experimental condition. When the execution time was expired, a questionnaire including manipulation checks and demographics was administered. Afterward, the experimenter evaluated the result of the innovation task.

\section{Experimental Task}

The innovation task was to build a construction from craft material that would secure an egg when dropped from a height of $2 \mathrm{~m}$. For this task, participants were provided with different materials (e.g., paper, balloons, and strings). The goal of the task was to create a construction that was most secure and original with as little material as possible (see supplemental materials). In line with results from pretests, participants had 30 min for the task completion. This specific task was chosen as it requires the generation of new and useful ideas and the implementation of ideas to achieve an innovative construction (West \& Farr, 1990).

\section{Experimental Manipulations}

We manipulated three leadership conditions through confederates that acted as leaders. The confederates were 
six female research assistants (two per condition) on average 23.5 years old $(S D=2.88)$.

To standardize leader behavior within conditions, sentences for the no leadership condition and for opening and closing leader behaviors were predefined based on the existing literature (see Table 1; Rosing et al., 2011; Zacher \& Rosing, 2015). Prior to data collection, the confederates were trained in accordance with the experimental conditions. The initial training session took $2-5 \mathrm{hr}$ with a follow-up session of $1 \mathrm{hr}$. During the training session, confederates learned the behavior they needed to show during the task completion depending on their leadership condition. They were instructed not to interact with the participants aside from task-related conversations that they could conduct with the standardized sentences.

Confederates in the no leadership condition learned that individuals should work self-organized within innovation processes (Yang, 2015) and, thus, they were instructed to not intervene with the work of participants. To realize this situation in a socially appropriate manner and similar to a field setting, confederates in this condition worked on a different task in the same room during the experiment and used standardized sentences to answer any questions.

In the training for the sequential condition, confederates learned about opening and closing leader behaviors (Rosing et al., 2011) and a sequential model for the innovation process (Farr et al., 2003). In the experimental sessions, the confederates then applied opening leader behavior within the first $8 \mathrm{~min}$ and then switched to closing leader behavior

Table 1. Standardized sentences for the leadership manipulations

\begin{tabular}{ll}
\hline $\begin{array}{l}\text { Leadership } \\
\text { manipulation }\end{array}$ & Examples for standardized sentences \\
\hline $\begin{array}{l}\text { Opening leader } \\
\text { behavior }\end{array}$ & $\begin{array}{l}\text { You can take all the different materials and } \\
\text { consider whether they would help to secure the } \\
\text { egg. } \\
\end{array}$ \\
& Consider different directions for your ideas. \\
& You don't need to be afraid of mistakes - you \\
& can learn from them. \\
& If this idea doesn't work, you are still one step \\
& closer to a solution. \\
& For a good solution, it is helpful to plan how you \\
& are going to implement it. \\
Closing leader & Beware of the time. At the end you need to have \\
behavior & a finalized construction to take part in the \\
& competition. \\
& Think about the goal of the task; the egg needs \\
& to be secured for you to win the competition. \\
& For a good solution make sure that you work \\
& thoroughly and avoid mistakes. \\
& Decide for yourself how you solve the task. \\
& I don't know about that. \\
I don't have any ideas and I also need to keep \\
working on my own task. \\
Unfortunately, I don't have any time to engage in \\
your task.
\end{tabular}

for the remaining $22 \mathrm{~min}$ of task completion. Therefore, the timing was the only cue that indicated which leader behavior had to be shown. These timeframes resulted from pretests with the experimental task to represent the best possible sequential condition. In this condition, confederates took initiative without any cues from the situation and talked regularly using either opening or closing leader behavior depending on the timing.

In the flexible condition, confederates were trained to switch between opening and closing leader behaviors depending on situational cues. These confederates learned about the dynamic nature of the innovation process and that leaders should adjust their behavior depending on situational requirements. For the training of confederates in this condition, pretests were necessary to understand the changes in behavior for the specific innovation task used in this experiment. $N=17$ students participated in the pretest in the laboratory, where they worked on the innovation task. Afterward, research assistants coded the video recordings concerning creativity- and implementation-related behaviors. The coders subsequently identified changes in behavior and developed a category system for situational cues that signal a change from creativity to implementation and vice versa. After conducting these pretests, we used the resulting categories to design training situations. For instance, the participants voiced insecurity regarding the stability of the construction (e.g., "I am not sure whether this construction is stable enough to secure the egg."), and this functioned as a signal for the confederate to change to opening leader behavior (e.g., "You can take all the different materials and consider whether they would help to secure the egg.").

\section{Measures}

\section{Manipulation Check}

Participants rated opening and closing leader behaviors on seven items each (5-point scale ranging from $1=$ not at all to $5=$ very strongly; Zacher \& Rosing, 2015). An example item for the opening leader behavior scale is "The other person, who was in the room with me, gave room for my own ideas" $(\alpha=.72)$. An example for the closing leader behavior scale is "The other person, who was in the room with me, controlled adherence to rules" $(\alpha=.66)$.

As a manipulation check, we tested the difference between the leadership conditions concerning the participants' ratings of opening and closing leader behaviors using multivariate analysis of variance (MANOVA). We expected both the sequential and flexible leadership conditions to show significantly more opening and closing leader behaviors compared to the no leadership condition. Using Wilks' lambda, a significant difference between the conditions was identified, $\Lambda=.63, F(4,178)=11.58$, 
$p<.001$. Subsequent univariate ANOVA revealed a significant effect on opening leader behavior, $F(2,90)=19.9$, $p<.001$, and closing leader behavior, $F(2,90)=6.49$, $p=.002$. Post hoc comparison further clarified that more opening behavior was shown in the sequential ambidextrous leadership condition $(p=.001)$ and the flexible ambidextrous leadership condition $(p<.001)$, each compared to the no leadership condition. For the ratings of closing leader behavior, more leader behavior was shown in the sequential $(p=.006)$ and flexible $(p=.01)$ ambidextrous leadership condition, each compared to the no leadership condition. There were no significant differences between the flexible and sequential conditions, neither for opening $(p=.11)$ nor for closing leader behavior $(p=.94)$.

In a second step, we coded the confederates' sentences recorded in the videos to assess changes in leader behavior. Each sentence was coded as opening, closing, or no leader behavior according to the predefined standardized sentences. Two independent coders coded a video from each experimental group showing very good interrater reliability (no leadership: $\kappa=.96$, sequential ambidextrous leadership: $\kappa=.90$, and flexible ambidextrous leadership: $\kappa=.99$; Cohen, 1960). Accordingly, the standardized sentences in the remaining videos were coded, and the changes between opening and closing leader behaviors were counted. Furthermore, it was also evaluated whether these changes in behavior were appropriate with respect to the situational requirements.

We tested the differences concerning the changes in leader behavior with a $t$ test. We expected a significant difference between the sequential and flexible conditions, with greater changes in the flexible ambidextrous leadership condition. The analysis supported our assumption as it showed a significant difference between the sequential and flexible conditions, $t(58)=-6.38, p<.001$. Subsequent comparison of the means showed more changes in the flexible condition $(\bar{x}=6.76, S D=3.66)$ compared to the sequential ambidextrous leadership condition $(\bar{x}=2.04, S D=1.29)$. Contrary to our expectations, the sequential condition showed more than one change in leader behavior on average. However, there was one explicit change from opening to closing leader behavior in each task execution of this condition. Nonetheless, in some cases, the fact that confederates should act as naturally as possible led to small additional changes in behavior. Taken together, these results point to a successful leadership manipulation.

\section{Performance}

Innovation task performance was operationalized in two dependent variables: effectiveness and originality. First, effectiveness describes the degree to which the construction fulfilled the task goal. For this purpose, the construction was dropped from different heights up to $2 \mathrm{~m}$. Performance was scored depending on the height at which the egg broke. Second, originality was rated independently by the confederates as experts based on a rating scale (Barbot et al., 2019; De Dreu et al., 2008). A video from the completed construction was evaluated on a scale from $1=$ not original to $5=$ very original. A construction was defined as very original when it was radical, new, and unique compared to the other constructions (Amabile, 1988; Miron-Spektor \& Beenen, 2015). The interrater reliability for the originality score based on all constructions was very good, with intraclass correlation coefficient $($ ICC) $=.80$ (Shrout \& Fleiss, 1979). Accordingly, the ratings of the different coders were averaged per construction.

\section{Statistical Analysis}

We first calculated descriptive statistics for all variables and examined intercorrelations. To test our hypotheses, we examined differences between the three experimental groups with respect to innovation performance in terms of effectiveness and originality. Consequently, we tested group differences in the two dependent variables using a MANOVA.

Table 2. Descriptive statistics and correlations of study variables

\begin{tabular}{|c|c|c|c|c|c|c|c|c|c|c|}
\hline & M & $S D$ & 1 & 2 & 3 & 4 & 5 & 6 & 7 & 8 \\
\hline 1. Ratings opening leader behavior & 3.26 & 0.76 & & & & & & & & \\
\hline 2. Ratings closing leader behavior & 2.95 & 0.68 & .20 & & & & & & & \\
\hline 3. Codings opening leader behavior & 8.90 & 8.43 & $.57^{\star \star}$ & $.65^{\star \star}$ & & & & & & \\
\hline 4. Codings closing leader behavior & 15.37 & 13.46 & $.41^{\star \star}$ & $.41 * \star$ & $.85^{\star \star}$ & & & & & \\
\hline 5. Codings changes in leader behavior & 4.63 & 3.69 & $.39 * \star$ & .11 & $.51 * \star$ & .01 & & & & \\
\hline 7. Effectiveness (DV)a & 1.22 & 1.25 & -.05 & .03 & .02 & -.01 & -.05 & -.05 & & \\
\hline 8. Originality $(D V)^{\mathrm{b}}$ & 2.75 & 0.98 & .02 & .02 & -.01 & .01 & .08 & .11 & .14 & \\
\hline
\end{tabular}

Note. $N=93$. $\mathrm{DV}=$ dependent variable. Coded as ${ }^{\mathrm{a}} 1=0.25 \mathrm{~m}, 2=0.5 \mathrm{~m}, 3=0.75 \mathrm{~m}, 4=1.0 \mathrm{~m}, 5=1.25,6=1.5 \mathrm{~m}, 7=1.75 \mathrm{~m}, 8=2.0 \mathrm{~m}$. ${ }^{\mathrm{b}} 1=$ not original, $5=$ very original. ${ }^{*} p<.05,{ }^{\star *} p<.01$. 


\section{Results}

$M, S D$, and correlations of all study variables can be seen in Table 2. The table shows some significant correlations among the variables for coding of leader behavior. No significant correlations were found for the dependent variables, effectiveness and originality. In addition, Table 3 provides $M$ and $S D$ s of all study variables for each condition separately. In contrast to expectations, the means of effectiveness and originality were similar across conditions.

\section{Hypothesis Testing}

We hypothesized that participants receiving flexible ambidextrous leader behaviors show better innovation performance compared to the "no leadership" and the "sequential condition." To test this hypothesis, we conducted a MANOVA regarding the effects of leadership condition on both effectiveness and originality. Using Wilks' lambda, the results revealed no significant effects, $\Lambda=.99, F(4,178)=0.21, p=.93$. This suggests that there were no significant differences between the conditions in effectiveness and originality, and therefore, the hypothesis could not be supported.

\section{Discussion}

Our experiment represents a first attempt to manipulate flexible ambidextrous leadership in a laboratory setting to provide evidence for the effectiveness of a flexible adaptation of leader behaviors in the innovation process (Rosing et al., 2011). Unexpectedly, we did not find significant effects of the manipulated leadership conditions on innovation performance. The flexible application of ambidextrous leadership did not lead to higher innovation performance in the experimental task compared to a sequential application or the absence of leader behaviors.

The findings suggest that it is possible that the assumptions we derived from the model of ambidextrous leadership are not correct. Most previous research on ambidextrous leadership has used correlational study designs (e.g., Gerlach, Hundeling et al., 2020; Zacher et al., 2016), which may have resulted in inflated relationships due to common method variance. However, recent experimental evidence suggests that opening and closing leader behaviors influence follower behavior and performance, at least under some circumstances (Gerlach, Heinigk et al., 2020; Klonek et al., 2020). Specifically, an experimental study by Gerlach, Henigk et al. (2020) examined the separate effects of opening and closing leader behaviors on innovation performance. This study provides evidence that opening and closing leader behaviors impact innovative performance when creativity and implementation task requirements are aligned with leader behaviors. In two experimental studies, Klonek et al. (2020) manipulated opening and closing leader behaviors, a sequential form of ambidextrous leadership, and transformational leadership, and examined the effects on innovation performance. Opening and closing leader behaviors influenced exploration and exploitation behaviors, respectively, in one of the two studies. In addition, only one of the two studies provided partial evidence that a sequential form of ambidextrous leadership led to higher innovation performance than either opening, closing, or transformational leader behaviors alone. Taken together, the experimental evidence for the causal effects of opening and closing leader behaviors on innovation performance is mixed, indicating that moderating influences - such as the alignment of leader behaviors with task requirements - are likely. Considering the results of the present study, it may be that the lack of differences in innovation performance between flexible and sequential ambidextrous leadership is due to flexible leadership not being better suited to promote innovation

Table 3. Descriptive statistics for leadership conditions

\begin{tabular}{|c|c|c|c|c|c|c|}
\hline & \multicolumn{2}{|c|}{ No leadership $(N=33)$} & \multicolumn{2}{|c|}{$\begin{array}{c}\text { Sequential } \\
\text { ambidextrous } \\
\text { leadership }(N=27)\end{array}$} & \multicolumn{2}{|c|}{$\begin{array}{c}\text { Flexible ambidextrous } \\
\text { leadership }(N=33)\end{array}$} \\
\hline & M & $S D$ & M & SD & M & SD \\
\hline Ratings opening leader behavior & 2.73 & 0.47 & 3.37 & 0.61 & 3.70 & 0.79 \\
\hline Ratings closing leader behavior & 2.62 & 0.59 & 3.15 & 0.54 & 3.10 & 0.76 \\
\hline Codings opening leader behavior & 0.03 & 0.17 & 14.75 & 3.64 & 13.00 & 8.13 \\
\hline Codings closing leader behavior & 0.12 & 0.42 & 29.30 & 7.17 & 19.24 & 7.76 \\
\hline Codings changes in leader behavior & & & 2.04 & 1.29 & 6.76 & 3.66 \\
\hline Effectiveness (DV)a & 1.27 & 1.21 & 1.07 & 1.11 & 1.30 & 1.42 \\
\hline Originality $(\mathrm{DV})^{\mathrm{b}}$ & 2.75 & 1.09 & 2.57 & 0.99 & 2.82 & 0.87 \\
\hline
\end{tabular}

Note. $N=93 . \mathrm{DV}=$ dependent variable. Coded as ${ }^{\mathrm{a}} 1=0.25 \mathrm{~m}, 2=0.5 \mathrm{~m}, 3=0.75 \mathrm{~m}, 4=1.0 \mathrm{~m}, 5=1.25,6=1.5 \mathrm{~m}, 7=1.75 \mathrm{~m}, 8=2.0 \mathrm{~m} .{ }^{\mathrm{b}} 1=$ not original, $5=$ very original. 
performance than a sequential leadership approach. As none of the previous - correlational or experimental - studies examined flexible leadership, more definite conclusions about the role of flexibility for (ambidextrous) leadership cannot be drawn at this time.

In addition, some methodological shortcomings might have influenced the results. Confederates talked a lot during task completion in the active leadership conditions, which could have impeded participants' feeling of autonomy. A one-way ANOVA on the number of sentences showed that confederates talked much more in both active conditions $(M=78.04$ and $M=62.97)$ compared to the no leadership condition, $M=6.94, F(2,90)=83.23, p<.001$. Thus, participants in the active conditions might have felt more controlled, which, in turn, may have reduced their motivation and innovation performance (Liu et al., 2011; Shalley \& Perry-Smith, 2001; Zhou, 2003). Investigating the impact of the intensity of leadership on creative and innovative processes, and the role of autonomy in the leader-follower relationship, is an interesting avenue for future research. Moreover, individual differences in, for example, the need for autonomy or the need for leader support might play a crucial role in this context (Herrmann \& Felfe, 2013).

\section{Theoretical and Methodological Contributions}

Our study contributes to research on ambidextrous leadership by investigating the causal influences of flexible changes between opening and closing leader behaviors on innovation performance (Rosing et al., 2011; Zacher et al., 2016; Zacher \& Rosing, 2015). Research on ambidextrous leadership shows that the interaction of opening and closing leader behaviors is positively related to innovation performance (Zacher \& Rosing, 2015; Zacher \& Wilden, 2014). However, these studies did not consider the flexible adaptation in line with situational requirements, and this is addressed in the presented experiment. We did not find any significant effects, and therefore, the flexible adaptation of opening and closing leadership did not lead to superior performance. Therefore, we show initial insights into the effects of flexible leadership in innovation processes.

Additionally, this study adds to the leadership literature as we provide a possibility concerning the manipulation of a flexible leadership approach in a controlled setting. Using confederates in this regard seems promising as they can act dynamically depending on situational requirements. Leadership research aims to analyze the influence leaders have on follower behaviors and performance outcomes (Fischer et al., 2017). For this purpose, controlled settings such as randomized experiments are called for (Antonakis, 2017; Antonakis et al., 2010; Hughes et al., 2018). As interactions between leaders and followers and especially their communication are central to many leadership theories (Gottfredson \& Aguinis, 2017; Hofmans et al., 2019; Rosing et al., 2011), we also need to examine the causal effects of these interactions. This is especially relevant for leadership models that incorporate leader behaviors as a flexible reaction to situational requirements, such as the ambidextrous leadership model (Rosing et al., 2011).

\section{Limitations and Future Research}

Our experiment demonstrates the challenges related to examining flexible leadership and further provides ideas for future research. As this was a first approach to the standardization of flexible leadership, some shortcomings with respect to the internal and external validity need to be considered. In terms of internal validity, the correlations between the codings and ratings of leadership behavior raise some concerns regarding the construct validity of both opening and closing leadership behaviors. Following the logic of a multitrait-multimethod matrix, we would expect higher correlations among different measures (ratings and codings) of the same construct than among the same type of measurement of different constructs. However, this was not the case (Table 2).

In terms of external validity, the experimental task might have differed from innovation projects in organizational practice. In the experimental task, creativity was necessary to find a successful solution. However, the implementation - the actual crafting of the construction - was very timeconsuming. Therefore, changes in leader behavior might not have been as necessary and appropriate as in innovation processes in an organizational context. Thus, one suggestion for future research is to design an experimental task that participants can work on for longer periods of time, similar to innovation processes in the field, to increase both internal and external validity. For example, participants could work outside the laboratory and come in for meetings in which leader behavior could be manipulated. These meetings could lead to a stronger manipulation, as the leader behaviors can be shown and changed more often, without impeding task completion. Another restriction of external validity common to experimental designs has to do with the confederates (Antonakis, 2017; Highhouse, 2009). Compared to such confederates, the sources of influence and power in the organizational context are more complex and different influences need to be considered (Subašić et al., 2011). Thus, future studies should also regard the flexible interplay of opening and closing leader behavior in field studies to receive realistic insights. Field experiments might be an optimal solution to establish a realistic context and the possibility to provide causal evidence. 


\section{Conclusion}

The goal of this article was to investigate the flexible adaptation of ambidextrous leader behaviors within a standardized setting. We did not find the proposed effects, which suggests that the effects of flexible leadership might not be as strong as expected and need further attention in future research. For example, the implementation of flexible leadership based on interactions within a laboratory setting is necessary. Innovation and a flexible approach to working are highly relevant in today's business world (Halbesleben et al., 2003; Rosing et al., 2011). Thus, it is a central challenge for future leadership research to further consider how we can empirically investigate flexible and adaptive leadership especially with respect to causal conclusions (Antonakis, 2017; Antonakis et al., 2010). Thus, it is necessary to consider different formats to investigate flexible adaptation of leader behaviors in controlled settings.

\section{References}

Amabile, T. M. (1988). A model of creativity and innovation in organizations. Research in Organizational Behavior, 10, 123-167.

Amabile, T. M., \& Pratt, M. G. (2016). The dynamic componential model of creativity and innovation in organizations: Making progress, making meaning. Research in Organizational Behavior, 36, 157-183. https://doi.org/10.1016/j.riob.2016.10.001

Andriopoulos, C., \& Lewis, M. W. (2009). Exploitation-exploration tensions and organizational ambidexterity: Managing paradoxes of innovation. Organization Science, 20(4), 696-717. https://doi. org/10.1287/orsc.1080.0406

Antonakis, J. (2017). On doing better science: From thrill of discovery to policy implications. The Leadership Quarterly, 28(1), 5-21. https://doi.org/10.1016/j.leaqua.2017.01.006

Antonakis, J., Bendahan, S., Jacquart, P., \& Lalive, R. (2010). On making causal claims: A review and recommendations. The Leadership Quarterly, 21(6), 1086-1120. https://doi.org/10.1016/j.leaqua.2010.10.010

Barbot, B., Hass, R. W., \& Reiter-Palmon, R. (2019). Creativity assessment in psychological research: (Re)setting the standards. Psychology of Aesthetics, Creativity, and the Arts, 13(2), 233-240. https://doi.org/10.1037/aca0000233

Blanchard, K. H., Zigarmi, D., \& Nelson, R. B. (1993). Situational leadership after 25 years: A retrospective. Journal of Leadership Studies, 1(1), 21-36. https://doi.org/10.1177/107179199300100104

Bledow, R., Frese, M., Anderson, N., Erez, M., \& Farr, J. (2009). A dialectic perspective on innovation: Conflicting demands, multiple pathways, and ambidexterity. Industrial and Organizational Psychology: Perspectives on Science and Practice, 2(3), 305-337. https://doi.org/10.1111/j.1754-9434.2009.01154.x

Bosco, F. A., Aguinis, H., Singh, K., Field, J. G., \& Pierce, C. A. (2015). Correlational effect size benchmarks. The Journal of Applied Psychology, 100(2), 431-449. https://doi.org/10.1037/a0038047

Cohen, J. (1960). A coefficient of agreement for nominal scales. Educational and Psychological Measurement, 20(1), 37-46. https://doi.org/10.1177/001316446002000104

Cooper, R. G. (1990). Stage-gate systems: A new tool for managing new products. Business Horizons, 33(3), 44-54. https://doi.org/ 10.1016/0007-6813(90)90040-1
De Dreu, C. K. W., Baas, M., \& Nijstad, B. A. (2008). Hedonic tone and activation level in the mood-creativity link: Toward a dual pathway to creativity model. Journal of Personality and Social Psychology, 94(5), 739-756. https://doi.org/10.1037/0022-3514. 94.5.739

Farr, J. L., Sin, H.-P., \& Tesluk, P. E. (2003). Knowledge management processes and work group innovation. In L. V. Shavinina (Ed.), International handbook on innovation (pp. 574-586). Elsevier Science Ltd.

Faul, F., Erdfelder, E., Buchner, A., \& Lang, A.-G. (2009). Statistical power analyses using $G^{\star}$ Power 3.1: Tests for correlation and regression analyses. Behavior Research Methods, 41(4), 1149-1160. https://doi.org/10.3758/BRM.41.4.1149

Faul, F., Erdfelder, E., Lang, A.-G., \& Buchner, A. (2007). G*Power 3: A flexible statistical power analysis program for the social, behavioral, and biomedical sciences. Behavior Research Methods, 39(2), 175-191. https://doi.org/10.3758/BF03193146

Fiedler, F. E. (1971). Validation and extension of the contingency model of leadership effectiveness: A review of empirical findings. Psychological Bulletin, 76(2), 128-148. https://doi.org/10. 1037/h0031454

Fischer, T., Dietz, J., \& Antonakis, J. (2017). Leadership process models: A review and synthesis. Journal of Management, 43(6), 1726-1753. https://doi.org/10.1177/0149206316682830

Gerlach, F., Heinigk, K., Rosing, K., \& Zacher, H. (2020). Aligning leader behaviors with innovation requirements improves performance: An experimental study. Frontiers in Psychology, 11, 1332. https://doi.org/10.3389/fpsyg.2020.01332

Gerlach, F., Hundeling, M., \& Rosing, K. (2020). Ambidextrous leadership and innovation performance: A longitudinal study. Leadership \& Organization Development Journal, 41(3), 383-398. https://doi.org/10.1108/LODJ-07-2019-0321

Gottfredson, R. K., \& Aguinis, H. (2017). Leadership behaviors and follower performance: Deductive and inductive examination of theoretical rationales and underlying mechanisms. Journal of Organizational Behavior, 38(4), 558-591. https://doi.org/10.1002/ job.2152

Halbesleben, J. R.B., Novicevic, M. M., Harvey, M. G., \& Buckley, M. R. (2003). Awareness of temporal complexity in leadership of creativity and innovation: A competency-based model. The Leadership Quarterly, 14(4-5), 433-454. https://doi.org/10.1016/ S1048-9843(03)00046-8

Havermans, L. A., Den Hartog, D. N., Keegan, A., \& Uhl-Bien, M. (2015). Exploring the role of leadership in enabling contextual ambidexterity. Human Resource Management, 54(S1), 179-200. https://doi.org/10.1002/hrm.21764

Herrmann, D., \& Felfe, J. (2013). Moderators of the relationship between leadership style and employee creativity: The role of task novelty and personal initiative. Creativity Research Journal, 25(2), 172-181. https://doi.org/10.1080/10400419.2013.783743

Highhouse, S. (2009). Designing experiments that generalize. Organizational Research Methods, 12(3), 554-566. https://doi.org/ 10.1177/1094428107300396

Hofmans, J., Dóci, E., Solinger, O. N., Choi, W., \& Judge, T. A. (2019). Capturing the dynamics of leader-follower interactions: Stalemates and future theoretical progress. Journal of Organizational Behavior, 40(3), 382-385. https://doi.org/10.1002/job. 2317

Hosking, D. M., \& Anderson, N. (2018). Organizing change and innovation: Challenges for European work and organizational psychology. In D. M. Hosking \& N. Anderson (Eds.), Organizational change and innovation (pp. 1-17). Routledge.

Hughes, D. J., Lee, A., Tian, A. W., Newman, A., \& Legood, A. (2018). Leadership, creativity, and innovation: A critical review and practical recommendations. The Leadership Quarterly, 29(5), 549-569. https://doi.org/10.1016/j.leaqua.2018.03.001 
Hunter, S. T., Thoroughgood, C. N., Myer, A. T., \& Ligon, G. S. (2011). Paradoxes of leading innovative endeavors: Summary, solutions, and future directions. Psychology of Aesthetics, Creativity, and the Arts, 5(1), 54-66. https://doi.org/10.1037/a0017776

Klonek, F. E., Gerpott, F. H., \& Parker, S. K. (2020). A conceptual replication of ambidextrous leadership theory: An experimental approach. The Leadership Quarterly. Advance online publication. https://doi.org/10.1016/j.leaqua.2020.101473

Liu, D., Chen, X.-P., \& Yao, X. (2011). From autonomy to creativity: A multilevel investigation of the mediating role of harmonious passion. Journal of Applied Psychology, 96(2), 294-309. https:// doi.org/10.1037/a0021294

Lord, R. G., Binning, J. F., Rush, M. C., \& Thomas, J. C. (1978). The effect of performance cues and leader behavior on questionnaire ratings of leadership behavior. Organizational Behavior and Human Performance, 21(1), 27-39. https://doi.org/10.1016/00305073(78)90036-3

Lubart, T. I. (2001). Models of the creative process: Past, present and future. Creativity Research Journal, 13(3-4), 295-308. https://doi.org/10.1207/S15326934CRJ1334_07

Mainemelis, C., Kark, R., \& Epitropaki, O. (2015). Creative leadership: A multi-context conceptualization. The Academy of Management Annals, 9(1), 393-482. https://doi.org/10.1080/19416520. 2015.1024502

Miron-Spektor, E., \& Beenen, G. (2015). Motivating creativity: The effects of sequential and simultaneous learning and performance achievement goals on product novelty and usefulness. Organizational Behavior and Human Decision Processes, 127, 53-65. https://doi.org/10.1016/j.obhdp.2015.01.001

Miron-Spektor, E., Ingram, A., Keller, J., Smith, W. K., \& Lewis, M. W. (2018). Microfoundations of organizational paradox: The problem is how we think about the problem. Academy of Management Journal, 61(1), 26-45. https://doi.org/10.5465/amj.2016.0594

Mumford, M. D., Scott, G. M., Gaddis, B., \& Strange, J. M. (2002). Leading creative people: Orchestrating expertise and relationships. The Leadership Quarterly, 13(6), 705-750. https://doi.org/ 10.1016/s1048-9843(02)00158-3

Podsakoff, P. M., \& Podsakoff, N. P. (2019). Experimental designs in management and leadership research: Strengths, limitations, and recommendations for improving publishability. The Leadership Quarterly, 30(1), 11-33. https://doi.org/10.1016/j.leaqua.2018.11.002

Rosing, K., Bledow, R., Frese, M., Baytalskaya, N., Johnson Lascano, J., \& Farr, J. L. (2018). The temporal pattern of creativity and implementation in teams. Journal of Occupational and Organizational Psychology, 91(4), 798-822. https://doi.org/10.1111/joop.12226

Rosing, K., Frese, M., \& Bausch, A. (2011). Explaining the heterogeneity of the leadership-innovation relationship: Ambidextrous leadership. The Leadership Quarterly, 22(5), 956-974. https:// doi.org/10.1016/j.leaqua.2011.07.014

Shalley, C. E., \& Gilson, L. L. (2004). What leaders need to know: A review of social and contextual factors that can foster or hinder creativity. The Leadership Quarterly, 15(1), 33-53. https://doi. org/10.1016/j.leaqua.2003.12.004

Shalley, C. E., \& Perry-Smith, J. E. (2001). Effects of social-psychological factors on creative performance: The role of informational and controlling expected evaluation and modeling experience. Organizational Behavior and Human Decision Processes, 84(1), 1-22. https://doi.org/10.1006/obhd.2000.2918

Shrout, P. E., \& Fleiss, J. L. (1979). Intraclass correlations: Uses in assessing rater reliability. Psychological Bulletin, 86(2), 420-428. https://doi.org/10.1037/0033-2909.86.2.420

Subašić, E., Reynolds, K. J., Turner, J. C., Veenstra, K. E., \& Haslam, S. A. (2011). Leadership, power and the use of surveillance: Implications of shared social identity for leaders' capacity to influence. The Leadership Quarterly, 22(1), 170-181. https://doi. org/10.1016/j.leaqua.2010.12.014
Vroom, V. H., \& Jago, A. G. (2007). The role of the situation in leadership. The American Psychologist, 62(1), 17-24. https://doi. org/10.1037/0003-066X.62.1.17

West, M. A., \& Farr, J. L. (Eds.). (1990). Innovation and creativity at work: Psychological and organizational strategies. Wiley.

Yang, I. (2015). Positive effects of laissez-faire leadership: Conceptual exploration. Journal of Management Development, 34(10), 1246-1261. https://doi.org/10.1108/JMD-02-2015-0016

Yukl, G. (2012). Effective leadership behavior: What we know and what questions need more attention. Academy of Management Perspectives, 26(4), 66-85. https://doi.org/10.5465/amp.2012. 0088

Yukl, G., Gordon, A., \& Taber, T. (2016). A hierarchical taxonomy of leadership behavior: Integrating a half century of behavior research. Journal of Leadership \& Organizational Studies, 9(1), 15-32. https://doi.org/10.1177/107179190200900102

Yukl, G., \& Mahsud, R. (2010). Why flexible and adaptive leadership is essential. Consulting Psychology Journal: Practice and Research, 62(2), 81-93. https://doi.org/10.1037/a0019835

Zacher, H., Robinson, A. J., \& Rosing, K. (2016). Ambidextrous leadership and employees' self-reported innovative performance: The role of exploration and exploitation behaviors. The Journal of Creative Behavior, 50(1), 24-46. https://doi.org/10. 1002/jocb.66

Zacher, H., \& Rosing, K. (2015). Ambidextrous leadership and team innovation. Leadership \& Organization Development Journal, 36(1), 54-68. https://doi.org/10.1108/lodj-11-2012-0141

Zacher, H., \& Wilden, R. G. (2014). A daily diary study on ambidextrous leadership and self-reported employee innovation. Journal of Occupational and Organizational Psychology, 87(4), 813-820. https://doi.org/10.1111/joop.12070

Zhou, J. (2003). When the presence of creative coworkers is related to creativity: Role of supervisor close monitoring, developmental feedback, and creative personality. Journal of Applied Psychology, 88(3), 413-422. https://doi.org/10.1037/0021-9010.88.3. 413

\section{History}

Received September 28, 2020

Revision received January 20, 2021

Accepted January 21, 2021

Published online June 1, 2021

\section{Acknowledgments}

We thank Svenja Grebe, Hannah Griesel-Przyklenk, Charlott Hoebel, Linnea Kleinsteuber, Ann-Kathrin Meise, Stefanie Meyer, Irina Michel, Karina Senftner, and Marie Ströbert for their support with the data collection and coding.

\section{Open Data}

The stage 1 manuscript was registered at the Open Science Framework at https://osf.io/srwcn/?view_only=84d9ae1860ec499c8929fbde4fo f86d9. The supplemental materials are available there as well.

\section{Funding}

This research was supported by a grant from the Deutsche Forschungsgemeinschaft (DFG), RO 4647/3-1. Open access publication enabled by University of Kassel.

\section{Friederike Gerlach}

Institute of Psychology

University of Kassel

Hollaendische Straße 36-38

34127 Kassel

Germany

f.gerlach@uni-kassel.de

friederike.gerlach@t-online.de 